\title{
Computer Use Profiles of 1,300 Award-Winning Educators
}

\author{
Betty J. Young
}

As educators and their schools dedicate moniesto obtaining computers and wiring schools for Internet connections, a central question remains: To what extent do teachers use computers and the Internet for instruction? In 1993, less than onehalf $(49 \%)$ of elementary and secondary teachers reported using computers at work with much of the use being in the areas of word processing and desktop publishing functions (Bureau of C ensus, 1993). By the fall of 1996 , only $20 \%$ of all public school teachers $(22 \%$ of elementary and $18 \%$ of secondary) reported using advanced telecommunications for teaching ( $\mathrm{N}$ ational $\mathrm{C}$ enter for Education Statistics [N CES], 1997). In spite of this under-utilization of computers in instruction, only $13 \%$ of schools, districts, or certification agencies mandated any form of teacher training and in over one half of the schools, teachers were left on their own to seek computer training opportunities (NCES, 1997).

Thereis a need to look more closely at the patterns of computer use among educators. By examining changes in the computer skill levels, types of computer uses, and perceived barriers or obstacles to greater computer use, there can be a clearer focus of efforts to expand the computer skill and usage of American educators. This study examined the background characteristics and computer use profiles of 1,300 teachers, administrators, and educational support professionals from 32 states. Those in the sample had received "O utstanding Educator" awards between 1987 and 1996 from a private foundation. The foundation collected facts and opinions from the award winners since the early 1990s. Given a particular interest in fostering the use of technology and computers in schools, this foundation requested a wealth of information regarding the educators' levels of involvement and expertise in this important area.

Thefollowing questions guided this investigation:

- What is the incidence of high levels of computer skills among highachieving educators?

- How are the computer skill levels distributed by gender, job type, years of experience, and community income levels?

- What is the degree of access to computers and the Internet among these educators?

- How are the educators using computers? H ow has this changed in recent years?

- W hat obstacles or barriers to computers and Internet use are seen by this population? H ow has this changed in recent years?

\section{Who We Studied and How Data Were Collected}

The group of 1,300 outstanding educators of this study were selected by the private foundation in conjunction with the D epartments of Education in 32 states in order to identify educators distinguished by achievement and promise. This population is particularly interesting for several reasons. First, this group of practitioners has been recognized for outstanding contributions and leadership in the field of education. Second, as of the spring of 1997, the outstanding educator group numbered 1,020 (1,300 of whom have remained active) from states throughout the country, so there is a substantial number of educators in this group. Third, these practitioners have been honored by a foundation that holds a high regard for educational technology, principally meaning computer use, as a means for school improvement. The foundation's mission statement illu- strates this purpose:

In education, the Foundation is committed to:

- strengthening the profession by recognizing and rewarding outstanding educators; by expanding their professional leadership and policy influence; and by encouraging talented young people to become educators. -Stimulating creativity and productivity among educators and students of all ages- especially by using technology to improve learning and teaching.

Fourth, the foundation maintains contact with the educators through conferences and other professional development activities that have astrong focus on educational technology. The vice president of the foundation's education division wrote:

\section{Education technology is only as effective as the educator who uses it, and we recognize that its potential imposes new demands on educators. This is why we have made it a priority to help educators become fluent in and think systematically about technology's use; to acquire and share expertise in technology's applications to education; and to integrate it with good practice.}

Therefore, this group of educators has had rich opportunities to develop skills and broad views of computer and Internet use in schools. Finally, the foundation has been collecting, by means of extensive surveys, opinions and information from the growing population since 1990. Thus, there are data collected over time related to computer use.

\section{Data Collection}

Award-winning educators were given an extensivesurvey in thefirst year of their award and yearly update surveys in the ensuing years. In some years, somewhat different versions of the surveys were given to teachers and to other educators so that the questions 
could be more tailored to the work experiences of each group. Some 14 different survey instruments were used since the first effort in 1990. The response rates for these surveys ranged from $90 \%$ to $100 \%$ probably in part because the foundation maintains contact with the outstanding educators through various activities. In all, over 4,000 surveys were completed from the awardees. Because approximately 138 awards were given each year, the number of outstanding educators answering a particular survey varied. Among the 14 survey forms, identical or similar questions in several areas allowed the comparison of key issues over time.

In order to make the comparisons presented here, the survey responses were converted into a central data base in the SPSS format using common identification numbers to merge data for each educator from all the surveys completed by that individual. Some variables, particularly the background characteristics, were available for the total sample of "active" awardees. In the case of some other questions, there were different segments of the total population who have provided information. The database allows the maximum number of subjects to be included in each comparison; however, it also means that the number of educators represented in different analyses varies. N evertheless, there are substantial numbers of participants who have contributed to each area.

Surveys consisted of many fixed response items related to background characteristics, computer access and use, and perceptions of obstacles to greater computer/technology use in schools. O n several of the most recent surveys, educators were asked to describe, in their own words, various aspects of their computer attitudes and uses as well as programs and areas of expertise that they viewed as their greatest accom- plishments. The responses on relevant open-ended questions were content analyzed using an emerging category system of post priori coding.
Characteristics and Computer Use of Outstanding Educators

Almost $60 \%$ of the sample were female, which is particularly interesting given the fact that only about one fourth of the educators are from the traditionally femalegroup of elementary teachers. The average length of experience in education was 25 years, and the bulk of the awardees had 16 to 35 years of experience. Especially in the earlier years of these awards, states selected very experienced educators. More recently, the foundation encouraged state departments of education to identify some earlier career educators in order to increase the "years of influence" that this growing cadre of outstanding teachers and administrators would have after the receipt of the awards. O ver onehalf ( $55 \%$ ) of the educators were associated with secondary schooling though there were a number in the group who were superintendents or directors with responsibility for all levels from K to12. As of 1996, the group was fairly evenly divided between classroom teachers (49\%) and administrators $(30 \%)$ or those in other education roles $(21 \%)$.

\section{Work Settings of Outstanding Educators}

The greatest proportion (36\%) of these recognized educators worked in the western United States. This fact resulted from the greater number of participating states in that region and the fact that several western states have been sel ecting outstanding educators in each of the 10 years included in the study. H owever, there were a substantial number of teachers from each of the major regions of the United States: M idwest, 25\%; South, 24\%; and N ortheast, $15 \%$.

M ost of the educators (58\%) worked in towns with populations between 2,500 and 49,999 residents. Another $27 \%$ of the awardees worked in small cities with between 50 and 500 thousand people. Very few of the educators (about $8 \%$ ) worked in districts with high proportions of students living in poverty as measured by the percentage of students receiving free lunch. N early one fourth of the home districts had less than $25 \%$ of the student body participating in the free lunch program. These findings had a special relevance because schools in more affluent areas have been shown to havegreater access to computersand other forms of technology (M artinez, 1994).

In two of the most recent studies (1995 and 1996), educators rated their level of computer skill on a scale of 1 to 10. A score of 1 indicated no experience; scores between 5 and 7 showed use of word processing, database, and spreadsheet; 8 and above represented those who also used on-line communications and multimedia tools for professional activities. Based on the 1996 report of 973 of the educators, the average skill level was 6.4, though the mode was 8 . For the 524 subjects who reported their skill levels in 1995 as well, there was an interesting change pattern. Forty-seven percent of the educators showed an increase in skill level in this one-year interval, indicating a high degree of professional development in this area. About 30\% did not change their rating. H owever, nearly one fourth of the awardees rated themselves lower on the second survey, possibly because the current explosion in educational computer and Internet opportunities gives one the feeling of losing ground just by staying at the same level of expertise. While some of these changes could be due to simple inconsistencies in self-reporting, $35 \%$ of the sample changed their report (up or down) by more than one level, which probably doesindicatereal changes in perception.

The computer skill levels were also examined by gender, by position, and by grade level (for those currently teaching). For this analysis, the 10 possible computer skill levels were divided into three groups: low (1 to 3 ), medium (4 to 7 ), and high (8 to 10). In examining thedistribution of computer skill by gender, there was a significant difference between males and females on self-reported computer skill levels $\left(x^{2}=\right.$ 15.36, $d f=2, p=.000$ ). W hile similar numbers of men and women were in 
the group with undeveloped computer skills, there were more males and fewer females in this group than would be expected if there were no systematic differences between them. In thegroup of high skill folks, there were more women, but more male educators than expected as well as fewer females were present. Generally, the men had higher computer skills than women.

Regarding the skill levels for job groups, there was a significant difference in the way computer skill was distributed within these groups. For example, there are fewer high skill educators than expected among administrators. Teachers, on the other hand, made a stronger showing in the top level and the strength in computer skill is among teachers in upper elementary grades and high school.

Thosenewest to the profession had experiences with word processing and other computer tools and many had advanced training in computers and Internet use. G enerally, skills of the least experienced awardees weresignificantly stronger than for those with the most years in education. This finding may be related to the foundation's call for younger practitioners and increased use of computer technology use as one suggested criterion for selection.

Finally, there appeared to be an advantage related to computer technology for schools with fewer studentsfrom families living in poverty. There was a significant difference between affluent and nonaffluent schools (as judged by percentage of students receiving free or reduced lunch) in terms of the computer skill level of educators who worked in these districts.

Access to Computers, Modems, and the Internet

About two thirds of the 1,300 awardees answered questions related to their level of access to computers, modems, and the Internet. Of the group responding, only 69 did not have access to a computer at school and only 105 did not have a computer available at home. Thus, homeand school access was fairly comparable. O ne fourth of all responding awardees did not have Internet connections at school; $34 \%$ did not have a connection from home.

\section{Computer Experience and Use}

In 1996, 725 awardees reported the number of years of computer experience they had. Of this group, $165(17 \%)$ reported having no experience. The average years of experience wasjust over eight years, which coincides with the large scale donation of Apple II computers to schools across America in 1983. The most frequent span of years was between 11 and 15, showing that $21 \%$ of this population had substantial computer experience. When the reported level of tech expertise was broken down by years of computer experience, it is interesting to note that it is not until computer experience reaches 11 years and beyond that the highly skilled computer users outnumber those reporting medium or low skills. Thus, it seems that many awardees were continuing to use computers in some ways but were not building onto their skills by using some of the more advanced applications that have been recently introduced.

In the 1996 update survey for those who had received awards between 1987 and 1995, educators were asked to indicate how frequently they used computers for four main purposes: instructing students or colleagues in computers, teaching their discipline, completing administrative tasks, and accessing the Internet for professional tasks. By far, the most frequent use related to handling administrative tasks. The second most frequent use related to accessing the Internet for instructional purposes. The two areas of computer-related teaching and accessing the Internet showed the greatest growth between 1995 and 1996.

Another view of the computer use of these educators was obtained by conducting a content analysis of three open-ended questions on the 1996 surveys. Educators indicated seven categories of responses given when the 1987 to 1995 groups were asked to describe five areas of expertise. Of the
542 educators who returned surveys, only 107 of them mentioned computerrelated expertise. H owever, these 107 awardees listed 246 separate types of tech-related expertise. The three main areas cited were instructional functions (e.g., desktop publishing, LEGO/ LO GO robotics, basic computer literacy courses), multimedia capabilities (e.g., PowerPoint, $\mathrm{H}$ yperstudio, CD -RO M ), and technology policy or planning (e.g., grant writing, wiring and installation, development of district technology plans). W hen these same 542 awardees were asked to describe five programs they were instrumental in developing, 128 of the respondents listed computerrelated or Internet programs, such asonline courses, tech fairs, computer camps, a virtual school program, and numerous websites and homepages for schools and districts.

The 138 educators who received their awards in 1996 were asked to describethe roleof computers and other technology in their classrooms or districts. Themost frequent role related to some aspect of instruction (e.g., publishing stories, use of CD-ROM books, Internet data sharing). Thenext most frequent computer use was communications and multimedia (e.g., video production and digital cameras as well as more conventional technologies such as tape recorders, overhead projectors, and VCRs). Thus, technology did not exclusively mean computersand Internet or e-mail use to many teachers. Additionally, many teachers chose to feature the noncomputer technology as evidence of their technological skill with little reference to computers.

\section{Obstacles to Computer Use in Schools}

Educators were asked to rank and describe obstacles to computer technology use. The 1993 survey asked 582 educators to indicate how frequently they encountered five possible obstacles: lack of training, lack of funds for equipment, lack of good software, lack of technical support, and insufficient electrical wiring. The greatest obstacle was funding for 
computer hardware with almost three fourths of the educators reporting this as somewhat or very much an obstacle. Lack of technical support, lack of training, and lack of good software were clustered very closely in second place. W iring was the least emphasized constraint.

The 1996 awardees were asked to describe obstacles to computer technology in their own words. These 138 educators named some 336 distinct barriers that were then grouped for analysis. Interestingly, the five obstacles from the first survey were the topranking items. M ost frequently, educators reported a shortage of funds for equipment. Second was the need for more training opportunities; however, in the race to connect classrooms to the Internet, insufficient wiring was the third most frequent problem cited. In addition to the five main problems were more general complaints of the lack of money, time, and space as well as the issue of reluctant teachers and parents.

\section{What It All Means}

This study provides an interesting view of the world of education from educators wewould most liketo support in their great contributions to American children. It was expected that the outstanding educators would provide a new perspective on the infusion of computer technology into the nation's schools; however, in some ways, they looked much like the other groups of teachers who have been studied in the past. W hat makes this remarkable is that these educators were recognized leaders who wereencouraged to develop skillsin using computers as tools as well as to infuse the use of related technologies and the Internet in their instructional programs. Thus, they had an enhanced opportunity to learn. Additionally, the numbers of educators from relatively affluent school districts should be an advantage, yet there were not astounding differences. A substantial number of educators reported the availability of computers at school and at home, but there were still al most $20 \%$ of the group who reported having no computer experience.

The results of this study shed light on an area that hasnot been well studied in the literature-the computer/technology use of administrators. In this study, theadministrators lagged behind teachers in the acquisition of computer skills. Even in their discussions of the role of computers and the Internet, their ideas were more general and full of buzzwords. Given the fact that thelack of administrative support was found to be an area of need, it would seem that training administrators would help them to support computer-enhanced instruction as well as increasing their effectiveness as an administrator.

The chief difficulty for all these educators wasthefunding of a computer infrastructure that includes the hardware, software, wiring/Internet access, and on-going technical support to allow educators to facilitate the incorporation of computer technology into their working schemes. Smart use of computers and the Internet in the service of enhancing student outcomes and school effectiveness can only take place when all the parts of the system are in place. Thus, there is a need for great coordination of efforts in this area.

$\mathrm{N}$ onetheless, there are indications that this group was participating in the groundswell of training efforts underway across the country as indicated by the increase in reported skill levels in a one-year period. W ithin this group weremany teachers and some administrators who were visionaries in the area of school computer use. There are many areas of this data that havenot yet been sufficiently explored. For example, subgroup analyses of the extreme computer skills (the 1s and the 10s) could yield important insights. Additionally, a look at only the administrators would add greatly to the current picture of computer use within schools and districts. The greatest limitation of any computer technology study is the rapid change in computer and Internet situations across the country. By the time a large set of data is analyzed, the complexion of the problem and the physical and human capital investments of districts may well have changed dramatically. N evertheless, the data provided by large-scale studies such as the present effort should assist districts in making more rational, data-driven decisions that will enhance the effectiveness of monies devoted to hardware, software, and training.

Dr. Betty J. Young is a professor in the School of Education at the U niversity of Rhode Island.

\section{References}

Bureau of Census. (1993). D igest of Education Statistics 1996, Table 416. Percent of workers, 18 years old and over, using computers on thejob.

Washington, DC: U.S. D epartment of Commerce.

M artinez, M. E. (1994). Access to information technologies among school-age children: Implications for a demographic society. Journal of the American Society for Information Science, 45(6), 395-400.

$\mathrm{N}$ ational Center for Education Statistics. (1997). Advanced telecommunications in U .S. public elementary and secondary schools, Fall 1996 (N CES 97-944). Washington, DC: Author.

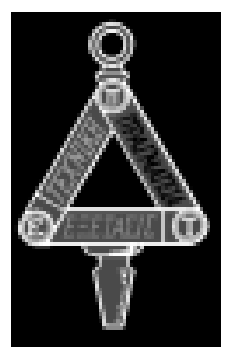

